\title{
Constructing Financial Supervision Mechanism for Government-sponsored Large-scale Sports Events
}

\author{
Yi-Qi SONG ${ }^{*, 1, a}$ \\ ${ }^{1}$ Department of Physical Education, North China Institute of Science and Technology, Hebei \\ 065201, China \\ songyq1981@yeah.net \\ ${ }^{*}$ Corresponding author
}

\section{Keywords: Financial Supervision Sports Events}

\begin{abstract}
With such research methods as referring to document literature and interviewing experts, this paper investigated the operation of large-scale sports events held in Shanghai, Beijing and Shenzhen and analyzed the financial supervision problems existed in government-sponsored large-scale sports events in recent years. From the three aspects of governmental supervision, social supervision and internal supervision, this paper putted forward the constructive mechanism of financial supervision for large-scale sports events, thus providing beneficial references to China's successful operation of sports events in the future.
\end{abstract}

\section{Introduction}

Sports industry has become one of the economic engines which enjoys the fastest growing pace, the widest influence and the most market potential in the global economy of the 21 century. Taking Shanghai as an example, in the recent decade, large-scale sports events have been held here continuously. Sports names as F1, Masters Cup, GP, Golden Grand Prix, Yao Ming and Liu Xiang have become familiar with every household. Various high-profile sports events held here have become a spectacle in Shanghai. In 2004, during the F1 Grand Prix in Shanghai, Shanghai enterprises undertaking the events received about 0.3 billion yuan from ticket sale. A large number of audiences came to Shanghai to watch the competition, thus bringing an income of nearly 2 billion yuan to its tourism, transportation and hotel industries. For example, for the 30 starred hotels of Jingjiang International Group in Shanghai, their income during the F1 increased 38 million yuan year on year, with a growth rate of $65.7 \%$.[2]

However, due to a lack of emphasis on the financial evaluation of the events, large-scale sports events as a whole enjoy great social benefits, but get a comparatively low return on investment, that is, they have low internal benefits. In terms of China's current economic structure and level, sports events are generally bid to host without considering accounting costs and internal benefits. On December 27, 2012, Shenzhen Auditing Bureau issued Announcement of Audit Findings on Financial Revenues and Expenditures and Venue Construction Projects for Shenzhen Universiade. According to the audit findings, five types of problems existed in Shenzhen Universiade: some of the projects didn't adopt centralized purchasing as stipulated, the self-purchasing program lacked standardization, some projects had false settlements and the deviation ratio was over $5 \%$.

The fact reminds us that we should analyze cautiously and act carefully when hosting large-scale sports events, and that not every sports event and operation pattern can bring great wealth. Behind large-scale sports events are huge investments made by the government. As to how to ensure that these investments are properly used and avoid corruption, it needs us to further improve the financial supervision mechanism for large-scale sports events. [2] 


\section{Research Objects and Methods}

With such research methods as referring to document literature and interviewing experts, this thesis investigates the characteristics and deficiencies of financial operation of large-scale sports events held in Shanghai, Beijing and Shenzhen.

\section{Research Conclusions}

Since large-scale sports events have large sizes and long periods, involve a wide range of projects and are closely related to the society, their costs and expenses are usually hard to estimate and the expenses incurred are hard to predict in detail. Domestically, major problems related to financial supervision in large-scale sports events are as follows: (1) relevant regulations of financial supervision are incomplete, lacking specific financial supervision regulations for sports events; (2) the financial information disclosure system is incomplete, so it is hard for the media and the public to know how the whole event budget is used specifically; (3) it lacks independent external audit supervision. Some sports events are totally undertaken by the government and don't receive external audit supervision which is strict and independent, thus unable to safeguard financial reliability; (4) it lacks daily financial supervision. [3]

\section{Countermeasures and Suggestions}

\section{Two Principles for Constructing Financial Supervision Mechanism for Sports Events}

The principle of cost-effectiveness is an important theory of economic concepts. It believes that action should be taken only when the extra benefits caused by it exceed the extra costs, that is, we should analyze and compare expenditure with income in economic activities and measure the gain and loss of economic behaviors. Seen from the general problems existed in financial supervision, on the one hand, supervision by over one government organizations and repeated supervision are quite common, which adds supervision costs and wastes public resources; on the other hand, the society and organizations lack internal supervision, thus unable to safeguard distribution of rights and supervision effectiveness and unable to show supervision benefits. Therefore, the cost-effectiveness must be carefully weighed in financial supervision of large-scale sports events. Governmental supervision and non-governmental supervision should maintain an appropriate balance, and each department for governmental supervision should also coordinate with each other. [3]

Principle of Dynamics .In the perspective of system, things change as time goes by. Everything is the unity of the statics and the dynamics. The mastery of the system lies in the understanding of the dynamics and the statics. Financial supervision mechanism should also follow the principle of dynamics, that is, supervision mechanism will not remain unchanged all the time, but it might be adjusted with the implementation of supervision and the assessment of supervision results. And such adjustments are for better standardizing and managing the financial activities of large-scale sports events. [2]

\section{Basic Thoughts for Constructing}

External Supervision Mechanism

Governmental Supervision

As one of the financial sponsors for large-scale sports events, the government should supervise the legality, reasonableness and effectiveness of the financial activities and financial relationships that have been organized. Meanwhile, since the government has authority in public rights, it enjoys high efficiency in supervision, thus playing a key guiding role in hosting large-scale sports events successfully. When designing specific supervision mechanism, we can make improvements in organizational mechanism and operational mechanism of the governmental supervision.

Organizational mechanism mainly deals with distribution of rights for governmental organizations exercising the supervision function, including the distribution of financial, tax, and audit supervision rights. It plays a dominant role in the process of financial supervision. When it comes to financial 
supervision for government-dominated large-scale sports events, it should clearly define the function of each department, and integrate the strengths of these departments. Operational mechanism mainly focuses on improving financial supervision regulations for large-scale sports events and establishing mandatory supervision system for financial information disclosure. As to information disclosure, the following problems shall be defined: (1) according to the levels of sports events, financial information of which levels shall be disclosed; (2) which relevant financial information should the sponsors of sports events disclose, and in what time and at what frequency; (3) how to let external supervisors grasp relevant information of the organization; (4) how to punish the sponsors of sports events who disobey the rules of disclosure. [3-4]

\section{Social Supervision}

Both social supervision and governmental supervision belong to external supervision, but compared with the latter, the authority of social supervision is comparatively weak. Meanwhile, due to the deficiencies of financial information disclosure, social supervision lacks motivation in supervising large-scale sports events. To improve the social financial supervision mechanism for large-scale sports events, we can work in three aspects: system, information and organization.

System-according to overseas experience, supervising large-scale sports events with the power of society in forms of laws, regulations or rules proves to be effective. It is suggested that the state shall issue relevant laws which stipulate that anyone, after applying to local administrative authority and being approved, can check various financial and management documents of government-sponsored large-scale sports events, such as financial accounts, financial budget and implementation reports, minutes of meetings, etc.

Information - to supervise financial behaviors, the supervisor should obtain relevant materials of the supervised object. The ways for social supervisors to obtain materials should be diversified, and special attention should be paid to the construction of information network. With the development of the Internet, more and more information demanders begin to know relevant information of large-scale sports events from the Internet. And financial information disclosed through Internet can not only exhibit e-media's characteristics of strong timeliness and high capacity, but also make it more convenient for social supervisors to check financial information. [1]

Organization - if necessary, special civil supervision organization shall be established to concentrate the power of social supervision. Third party supervision organizations are established overseas, which is worth learning from for the supervision pattern of various governmental departments. We suggest that by strengthening third party auditing, our country can authorize accounting firms to carry out financial supervision of large-scale sports events on behalf of scattered social supervisors, and establish special funds to pay auditing expenses.

\section{Internal Supervision Mechanism}

The internal supervision mechanism and external supervision mechanism of large-scale sports events are complementary to each other. It is far from enough to solely depend on external restrictions to standardize financial behaviors of large-scale sports events and promote the healthy development of organizations. We should combine the external restrictive supervision and the internal autonomic supervision. When it comes to internal supervisors for sports events, besides supervision groups divided according to responsibilities and hierarchies, such as sports bureau, functional departments and organization staff, individuals can also supervise financial activities of large-scale sports events as supervision individuals. [2-4]

On account of such problems as lacking internal supervision efficacy for large-scale sports events in current China, we can improve internal supervision mechanism in the following aspects: First, by improving the governance structure of large-scale sports events, we can lay a good environmental foundation for supervision implementation, such as establishing financial supervision committee, or through internal auditing supervision; strengthen daily supervision of organizational finance through these functional departments; Second, improve the motivation of internal supervision through internal supervision incentive mechanism, thus promoting supervision results. By strengthening incentives for senior executives, we can not only better attract senior executives and improve organizational 
administration, but also suppress the evil by incentives, thus restricting excess perquisite consumption. In nature, incentives are to increase people's initiatives, thus better promoting organizations to achieve autonomous supervision. [2-4]

\section{References}

[1]Yao Junfang. Research On the Financial Supervision Mechanism of Non-profit Organizations. Hunan University. Master Thesis, 2010.

[2]Ding Shu. The Research on Non-profit Organizations' Financial Supervision by the Government. Hunan University. Master Thesis, 20101.

[3]Zhang Yuanyuan. Study on Financial Supervision of State-owned enterprises Sichuan Academy of Social Secinces. Master Thesis, 2012.

[4]Zhu Taiqian. The Financial Evaluation Research of Large-scale Sports Events-A Case Study of National Games. Shanghai University of Sport. Master Thesis, 2010. 